www.nature.com/pj

\title{
Kinetics of the hydrolytic depolymerization of poly(ethylene terephthalate) under microwave irradiation
}

\author{
Shuzhen Zhang, Xiaofang Song, Dong Zhang and Yiguang Tian
}

The kinetic processes of poly(ethylene terephthalate) (PET) hydrolytic depolymerization under microwave irradiation were studied in detail. Potentiometric titration, ebullioscopy and the methods of thermogravimetric analysis (TGA) and scanning electron microscope (SEM) were used. The microwave depolymerization reaction of PET occurred in the interior and on the exterior of PET simultaneously and did not involve only one kinetic process. The depolymerization process was divided into at least two stages, for example, the stages before and after random chain scissioning. The corresponding activation energies were 142 and $378 \mathrm{~kJ} \mathrm{~mol}^{-1}$, respectively, which were much higher than the activation energy of the thermal depolymerization of heating. Polymer Journal (2011) 43, 811-815; doi:10.1038/pj.2011.73; published online 27 July 2011

Keywords: depolymerization; kinetics; microwave; mechanism; PET

\section{INTRODUCTION}

Microwave irradiation has been successfully applied to the depolymerization of some polymers, such as poly(ethylene terephthalate) (PET), polyamide-6 and polystyrene because of the short reaction time when it is used as an energy source. ${ }^{1-6}$ The kinetic studies of polymer microwave depolymerization have received much attention because of the non-thermal effects that are observed. The facts that the polymer depolymerizations could be accelerated by microwave irradiation, and that the depolymerization mechanism was a combination of regular and random chain scissioning have generally been accepted. $^{7-11}$

In terms of the applications of microwave irradiation, some of the kinetic processes of PET depolymerization have been studied, such as glycolytic and aminolytic depolymerizations of PET in a microwave reactor, which were conducted by Achilias et al. ${ }^{12,13}$ The activation energy $\left(E_{\mathrm{a}}\right)$ of the depolymerization reactions was evaluated by a simple kinetic model. Moreover, Achilias et al. ${ }^{14}$ reported the hydrolytic depolymerization of PET in an alkaline solution with a phase-transfer catalyst under microwave irradiation, and the $E_{\mathrm{a}}$ was also evaluated.

In our previous work, ${ }^{6}$ microwave irradiation, used as an energy source, was applied to PET hydrolytic depolymerization in pure water, and the chain-scissioning mechanism of PET depolymerization was preliminarily discussed. It is known that using microwave irradiation as an energy source causes thermal and non-thermal effects. Would the chain-scissioning mechanism of the polymer depolymerizations be changed by the non-thermal effects of microwave irradiation? What are the chain-scissioning mechanism and its kinetic behavior?
In this study, the kinetic processes and mechanisms of PET hydrolytic depolymerization using microwaves were investigated, and the chain-scissioning mechanism was further examined to confirm the non-thermal effects of microwave irradiation, effects for which the chemical reactions of small molecules cannot provide effective explanations. This paper provides a deeper understanding of the non-thermal effects of microwaves on chemical reactions.

\section{MATERIALS AND METHODS}

Chemicals

Pure PET resin was obtained in the form of fiber-grade commercial chips supplied by Liaoyang Petrochemical Fiber Company (Liaoyang City, China). The high-purity water used was prepared by triple distillation. The 1,1,2,2tetrachloroethane used for measuring the intrinsic viscosity, the phenol used for ebulliometry, and the chloroform, orthocresol and dimethyl sulfoxide used for end-group analysis were of analytical grade (all chemicals were provided by the Shanghai Chemical Reagent Factory, Shangai City, China).

\section{Viscosity-averaged molecular weight of PET}

The intrinsic viscosity of PET was $0.621 \mathrm{dlg}^{-1}$ (measured in a $60 / 40(\mathrm{w} / \mathrm{w}$ ) phenol/1,1,2,2-tetrachloroethane solution at $25^{\circ} \mathrm{C}$ ), corresponding to a viscosity-averaged molecular weight of 18912 , which was calculated from the following equation: intrinsic viscosity $=7.55 \times 10^{-4} \mathrm{M}^{0.685}{ }^{15}$

\section{Depolymerizations under microwave irradiation}

In our previous research work, ${ }^{16}$ we conducted a series of PET depolymerization experiments to determine the optimal reaction conditions; the optimal reaction temperature was $220^{\circ} \mathrm{C}$. For the studies of the kinetics and the mechanisms of PET depolymerization processes, the resulting differences from 
reaction temperatures of $200-220^{\circ} \mathrm{C}$ were not obvious, hence the reaction temperatures of 180,185 and $190^{\circ} \mathrm{C}$ were adopted. Moreover, there was enough depolymerization product, and the undepolymerized PET (i.e., partially depolymerized PET) was easy to determine (especially with thermogravimetric analysis (TGA) and scanning electron microscopy (SEM)) in the range of the reaction temperatures. The reaction time was controlled within the range of 90-480 $\mathrm{min}$, and a 30-min time interval for depolymerization at each temperature was used.

PET chips (2g) were precisely weighed and placed in a sealed 80-ml Pyrex glass vessel with $20 \mathrm{ml}$ of distilled water. Depolymerizations were performed at a certain controlled temperature in a microwave system (CEM Discover, CEM Corporation, Matthews, NC, USA) equipped with temperature and pressure sensors, and the power output of the microwave was controlled at $260 \mathrm{~W}$ without agitation. At the end of the experiment, the reaction vessel was cooled for 20 min under sealed conditions and then taken out of the microwave system. The solid mixture, which included the depolymerization product terephthalic acid and the undepolymerized PET, was separated from the solution by filtration with high-purity water to dissolve ethylene glycol and dried at $90^{\circ} \mathrm{C}$ to a constant weight.

\section{Methods}

Carboxyl-group concentration analysis of solid mixtures. One carboxyl group was produced when an ester bond was broken during the PET depolymerization process, and the number of carboxyl groups expressed the PET depolymerization degree quantitatively and directly. The carboxyl-group concentrations $\left(C_{\mathrm{COOH}}\right)$ of solid mixtures were determined by potentiometric titration according to Campanelli et al. ${ }^{17}$ The reference electrode was saturated calomel electrode, and a certain concentration of potassium hydroxide$\mathrm{C}_{2} \mathrm{H}_{5} \mathrm{OH}$ was used as the normal solution. The potentiometric titration was completed automatically by an auto potentiometric titrator.

Determination of the molecular weight. Determination of the molecular weight was important and significant for the kinetic studies of the depolymerization process ${ }^{18}$ and it qualitatively reflected the depolymerization degree of PET. The method of ebullioscopy was used to determine the number-average molecular weight $\left(M_{\mathrm{n}}\right)$ of the undepolymerized PET for its relatively lower range of molecular weights. The solid depolymerization mixtures were dissolved in a $10 \%$ potassium hydroxide solution and then filtered. The solid samples (i.e., the undepolymerized PET) were dried at $90^{\circ} \mathrm{C}$ to a constant weight. Atmospheric distillation was used to determine the boiling point of the undepolymerized PET dissolved in phenol according to the ebullioscopy for the molecular weight of the polymer.

TGA and SEM of the undepolymerized PET. The TGA of the undepolymerized PET was performed with TGA equipment (SDT Q600, TA Instruments, New Castle, DE, USA) at the rate of $10{ }^{\circ} \mathrm{Cmin}^{-1}$ under a nitrogen environment within the range of $30-700^{\circ} \mathrm{C}$. The SEM (JXA-840, JEOL, Tokyo, Japan) was used for the morphology analysis of the undepolymerized PET, which was put on a specimen stub, and deposited by vacuum evaporation with gold.

\section{RESULTS AND DISCUSSION}

Carboxyl-group concentrations and molecular weight versus time Both the changes in the $C_{\mathrm{COOH}}$ of the depolymerization reaction (solid dotted line) and the $M_{\mathrm{n}}$ of the undepolymerized PET (hollow dotted line) as a function of the depolymerization time for different temperatures are shown in Figure 1. The $C_{\mathrm{COOH}}$ increased and the $M_{\mathrm{n}}$ decreased with the reaction time. The $C_{\mathrm{COOH}}$ values were directly proportional to the temperature for a given depolymerization time. This result indicated that as the temperature rose, more carboxyl groups were produced and the depolymerization proceeded further.

It is worth noting that the changes of $C_{\mathrm{COOH}}$ appeared to regularly shift with the depolymerization time for different temperatures. This could be interpreted to mean that the PET molecular chain was quickly broken; this was due to the non-thermal effects of microwave irradiation on the depolymerization process. The change in $C_{\mathrm{COOH}}$ as a function of time was not a smooth curve, and this suggested that the

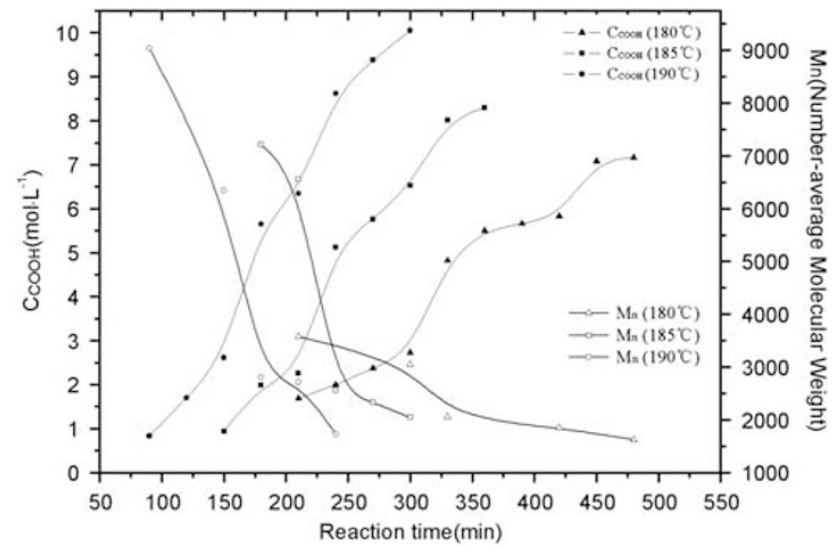

Figure 1 Carboxyl group concentration $\left(C_{\mathrm{COOH}}\right)$ of the depolymerization reaction (solid dotted line) and the number-average molecular weight $\left(M_{n}\right)$ of the undepolymerized polyethylene terephthalate (PET) (hollow dotted line) versus the depolymerization time under different temperatures.

microwave depolymerization of PET did not follow only one kinetic process.

The $M_{\mathrm{n}}$ of the undepolymerized PET was in the range of $10^{3}-10^{4}$, as shown in Figure 1. However, $M_{\mathrm{n}}$ became steady and the changes were incremental when its values dropped to a certain range (2000 $<M_{\mathrm{n}}<3000$ ). This finding was consistent with the results of related studies, which pointed to the fact that the molecular chain is broken to a certain extent in the process of PET hydrolysis. ${ }^{19}$ Moreover, there were additional clear drops in the value of the $M_{\mathrm{n}}$ at the depolymerization times of 150,210 and $300 \mathrm{~min}$ for the temperatures of $190^{\circ} \mathrm{C}$, $185^{\circ} \mathrm{C}$ and $180^{\circ} \mathrm{C}$, respectively, and this was in line with the results of the $C_{\mathrm{COOH}}$ changes for different temperatures.

At the same reaction time, as the temperature rose, more carboxyl groups were produced, a lower molecular weight was achieved, and the depolymerization of PET was more complete. At the same temperature, the decreases of $M_{\mathrm{n}}$ and the increases of $C_{\mathrm{COOH}}$ occurred to the same extent. Moreover, the $M_{\mathrm{n}}$ became steady, but the $C_{\mathrm{COOH}}$ kept increasing when the reaction comes to a period at different temperatures. This meant that there would be limitations on the further cracking of the molecular chain of PET for a certain period of time.

\section{TGA of the undepolymerized PET}

The results of PET depolymerization at $190^{\circ} \mathrm{C}$ were considered to be representative of the degree of PET depolymerization for the three different temperatures and especially for the morphologies seen in the SEM micrographs. Therefore, the TGA results of the undepolymerized PET at different reaction times (90-300 $\mathrm{min}$ ) at $190^{\circ} \mathrm{C}$ were selected for the qualitative analysis of the TGA, which is shown in Figure 2.

There was no evidence of changes between 90 and $150 \mathrm{~min}$ depolymerization time for TG, and this showed that the thermal stability of the undepolymerized PET was the same when the $M_{\mathrm{n}}$ changed. When the depolymerization time was longer than $210 \mathrm{~min}$, especially when it reached $240 \mathrm{~min}$, the thermal stability of the undepolymerized PET evidently declined with the rapid decrease of the $M_{\mathrm{n}}$. A sharp change in weightlessness appeared when the depolymerization time reached $300 \mathrm{~min}$, and this was confirmed by the thermal stability law for the molecular weight changes of $\mathrm{PET}^{20}$ that is, the hot weightlessness increased quickly with the decreases in PET for low degrees of polymerization. 


\section{SEM of the undepolymerized PET}

The surface and the section morphologies of the undepolymerized PET at the depolymerization times of 120 and $180 \mathrm{~min}$ observed by SEM are shown in Figures 3a-d, respectively; the ratio of water to PET was 10:1, and the temperature was $190^{\circ} \mathrm{C}$.

The surface morphology of the undepolymerized PET at the depolymerization time of $120 \mathrm{~min}$ at $190{ }^{\circ} \mathrm{C}$ is shown in Figure $3 \mathrm{a}$. The surface of the undepolymerized PET contained faults and a partial

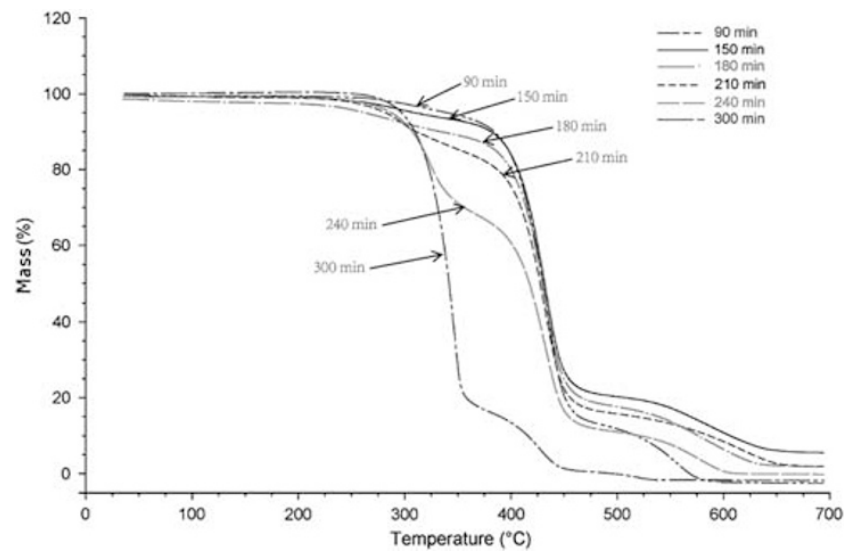

Figure 2 Thermogravimetric analysis (TGA) of the undepolymerized polyethylene terephthalate (PET) at different depolymerization times. A full color version of this figure is available at Polymer Journal online. upheaval plane structure. Compared with the surface, the inner section of the undepolymerized PET was obviously pitted with many small holes for the same conditions shown in Figure $3 \mathrm{~b}$. We confirmed that the depolymerization reaction occurred in the interior and on the exterior (that is, inside and on the surface) of the PET simultaneously. This behavior suggested that the mechanism of PET depolymerization involved random chain scissioning. As time passed, the fault and partial upheaval plane structure of the undepolymerized PET surface collapsed gradually, as shown in Figure 3c. It was interesting that so many obvious cracks and massive holes formed in the interior of the undepolymerized PET over time, as shown in Figure $3 \mathrm{~d}$. It was confirmed that many ester bonds in the PET interior were broken by the non-thermal effects of microwave irradiation during the depolymerization process, and this was consistent with the results of the $M_{\mathrm{n}}$ determination in which the PET chain was broken rapidly to the same degree as the massive low-molecular-weight polymers.

\section{Mechanisms of chain scissioning}

All the results-the carboxyl group concentration $C_{\mathrm{COOH}}, M_{\mathrm{n}}$ and the SEM micrographs-suggested that there was a mechanism in which the depolymerization of PET involved random chain scissioning and resulted in the non-thermal effects of microwave irradiation. There were at least two different periods in the depolymerization reaction. In the initial period, the molecular weight dropped and the monomer (which would be hydrolyzed into terephthalic acid and ethylene glycol) content increased gradually when the molecular chain was
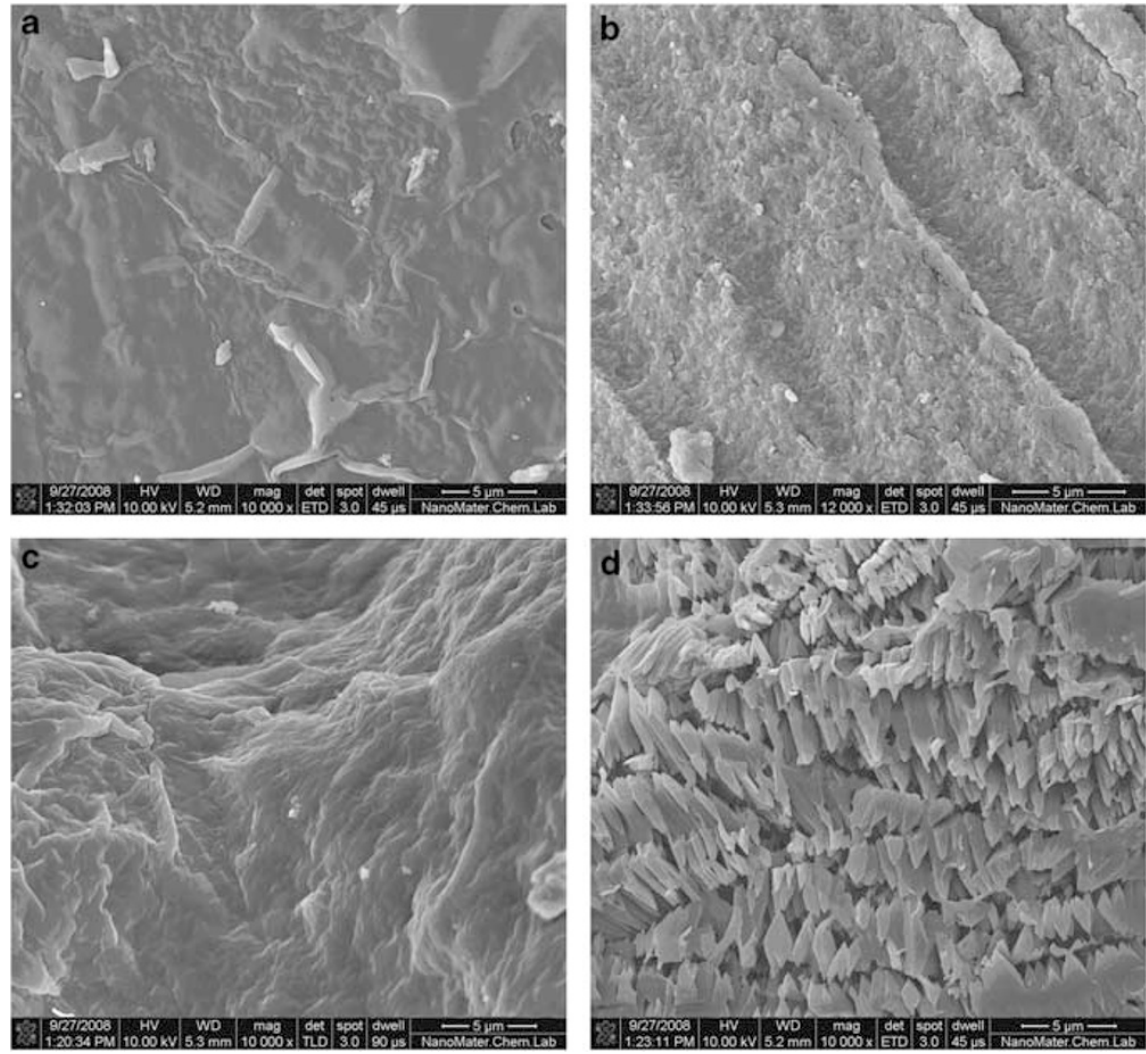

Figure 3 (a) The surface morphology of the undepolymerized polyethylene terephthalate (PET) at the depolymerization time of 120 min at $190{ }^{\circ} \mathrm{C}$. (b) The section morphology of the undepolymerized PET at the depolymerization time of $120 \mathrm{~min}$ at $190^{\circ} \mathrm{C}$. (c) The surface morphology of the undepolymerized PET at the depolymerization time of $180 \mathrm{~min}$ at $190^{\circ} \mathrm{C}$. (d) The section morphology of the undepolymerized PET at the depolymerization time of 180 min at $190^{\circ} \mathrm{C}$ 
mainly ruptured by the depolymerization. After that, the molecular weight dropped, and the monomer content increased rapidly when PET chains were broken randomly. Finally, the molecular weight of the undepolymerized PET decreased toward stableness, and the monomer content increased gradually. Therefore, the chain scissioning of PET depolymerization under microwave irradiation involved regular, then random, then regular processes.

\section{Kinetic model}

The study of PET hydrolysis in the solid state received much attention many years ago. Miyagi et al. ${ }^{21}$ studied the etching of crystalline PET by hydrolysis, Campanelli et al. ${ }^{17}$ studied the kinetics of PET hydrolysis at high temperatures, and Thominette et al. ${ }^{22,23}$ studied the water-sorption characteristics of PET amorphous foil.

It is well known that the frequency of the microwave system is $2450 \mathrm{MHz}$, which is the effective absorption frequency for water. ${ }^{24}$ The kinetic behaviors should be different in different media. This study involved PET depolymerization only in pure water, and the depolymerization product terephthalic acid of the solid mixtures was in a microliter state, which was obtained by filtration after cooling for $20 \mathrm{~min}$ from $\geqslant 160{ }^{\circ} \mathrm{C}$. Therefore, it was assumed that the produced terephthalic acid was in a 'quasi-melt' state during the processes of PET depolymerization in the microwave system. The PET depolymerization under microwave irradiation was a process in which the chemical bond of ester was broken by water, which could be considered to be consistent with the study of PET hydrolysis at high temperatures by Campanelli et al. ${ }^{17}$ to some extent:

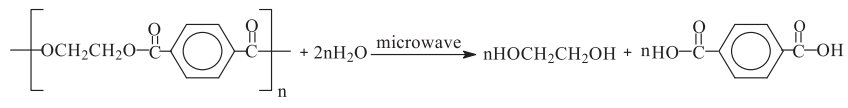

The rate of depolymerization of PET can be expressed as follows:

$$
\ln \frac{1}{1-e}=k C_{H_{2} \mathrm{O}} t
$$

The reaction extent $e$ can be calculated as follows:

$$
e=\left(C_{\mathrm{COOH}}-C_{\mathrm{COOH}, 0}\right) /\left(C_{E L, 0}-C_{\mathrm{COOH}, 0}\right)
$$

$C_{\mathrm{EL}}$ is the concentration of ester linkages, $C_{\mathrm{COOH}, 0}$ refers to the carboxyl group concentration at time $=0$, and $C_{\mathrm{EL}, 0}$ was the initial concentration of ester linkages. The rate constant ' $k$ ' could be determined from a plot of $C_{\mathrm{H}_{2} 0}^{-1} \ln [1 /(1-e)]\left(\mathrm{C}_{\mathrm{H}_{2} \mathrm{O}}\right.$ was considered a constant) versus time, and the relationships for different temperatures are shown in Figures 4, 5 and 6.

Because the microwave chemical reaction of PET depolymerization did not involve only one kinetic process, the depolymerization could be divided into at least two stages: the a-stage $\left(3000<M_{n}<9000\right)$ was the period before the PET random chain scissioning, and the b-stage $\left(2000<M_{\mathrm{n}}<3000\right)$ was the period after the PET random chain scissioning. The stage between $\mathrm{a}$ and $\mathrm{b}$ was the period of the PET random chain scissioning, resulting from the non-thermal effects of microwave irradiation.

From the results that are shown in Figures 4-6, it can be seen that there were two rate constants for the different temperatures, and they were consistent with the changes in the molecular weight. Furthermore, this fact indicated that in the same reaction stage, a higher reaction temperature meant a larger constant. The rate constants of the b-stage were larger than those of the a-stage for different temperatures, and the differences in the rate constants increased gradually as the temperature rose (as shown in Table 1).

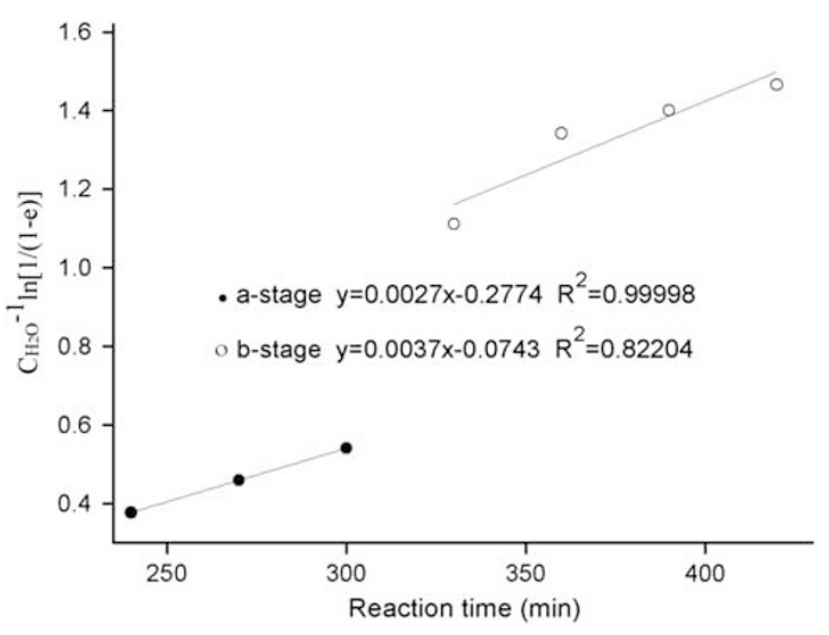

Figure 4 Relationship between $C_{H_{2} \mathrm{O}}^{-1} \ln [1 /(1-e)]$ and the reaction time at $180^{\circ} \mathrm{C}$.

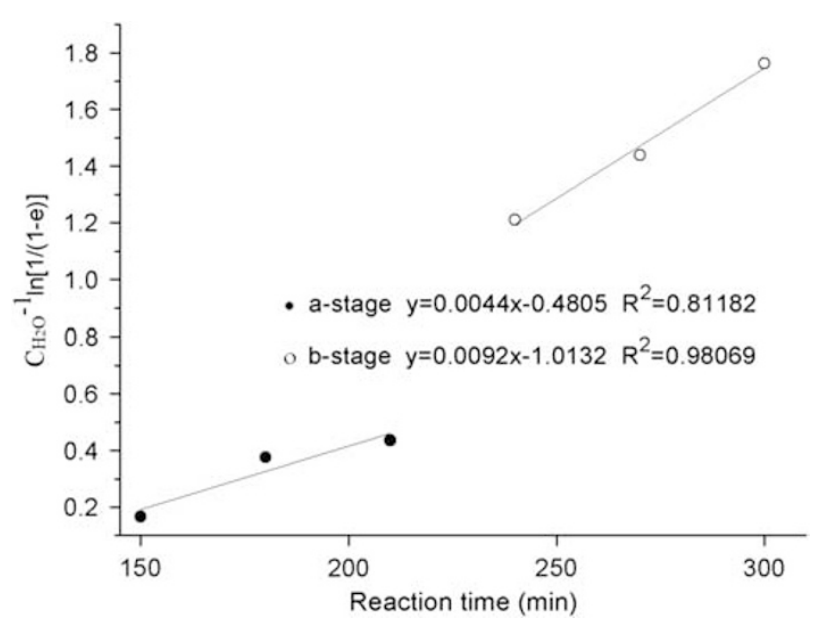

Figure 5 Relationship between $C_{H_{2} \mathrm{O}}^{-1} \ln [1 /(1-e)]$ and the reaction time at $185^{\circ} \mathrm{C}$.

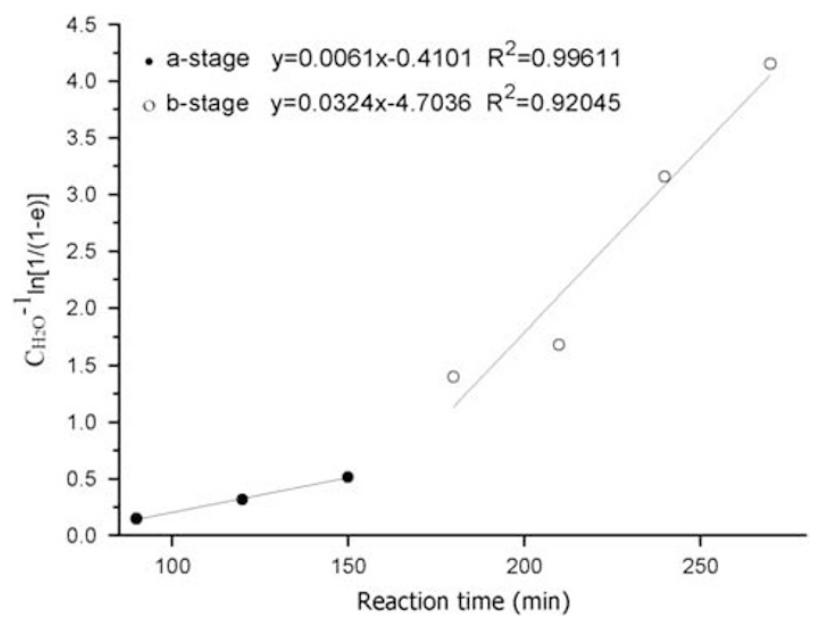

Figure 6 Relationship between $C_{H_{2} O}^{-1} \ln [1 /(1-e)]$ and the reaction time at $190^{\circ} \mathrm{C}$.

The Arrhenius plots of two different reaction stages are shown in Figure 7, and the corresponding $E_{\mathrm{a}}$ is listed in Table 1.

From the results of the table, it can be seen that the $E_{\mathrm{a}}$ of the b-stage was more than double that of the a-stage. Furthermore, the $E_{\mathrm{a}}$ of the 
Table 1 Rate constants of the reaction stages with different range of $M_{\mathrm{n}}$ in different temperature, and its activation energy for PET depolymerization reaction

\begin{tabular}{lcccc}
\hline $\begin{array}{l}\text { Reaction } \\
\text { stage }\end{array}$ & $\mathrm{M}_{n}$ & $\begin{array}{c}\text { Temperature } \\
\left({ }^{\circ} \mathrm{C}\right)\end{array}$ & $\begin{array}{c}\mathrm{k} \\
\left(\mathrm{kg} \mathrm{mol}^{-1} \mathrm{~min}^{-1}\right)\end{array}$ & $\begin{array}{c}\mathrm{E}_{\mathrm{a}} \\
\left(\mathrm{kJ} \mathrm{mol}^{-1}\right)\end{array}$ \\
\hline $\mathrm{a}$ & & 180 & 0.0027 & 142 \\
& \multirow{3}{*}{$3000<M_{\mathrm{n}}<9000$} & 185 & 0.0045 & \\
$\mathrm{~b}$ & 190 & 0.0061 & \\
& & 180 & 0.0037 & 378 \\
& $2000<M_{\mathrm{n}}<3000$ & 185 & 0.0092 & \\
& & 190 & 0.0324 &
\end{tabular}

Abbreviations: $E_{\mathrm{a}}$, activation energy; $k$, rate constant; $M_{\mathrm{n}}$; number-average molecular weight; $\mathrm{PET}$, polyethylene terephthalate;

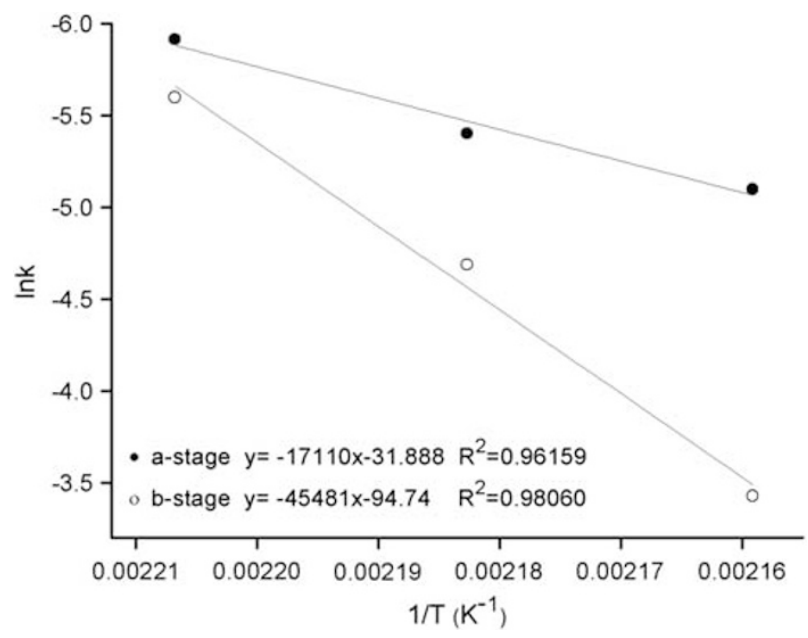

Figure 7 Arrhenius plots of the two different reaction stages.

a-stage was slightly larger than $123 \mathrm{~kJ} \mathrm{~mol}^{-1}$, which is the value for PET that was hydrolyzed at a high temperature by heating, ${ }^{17}$ and the $E_{\mathrm{a}}$ of the b-stage was much higher than that of the thermal depolymerization. It can be assumed that microwave irradiation can make PET depolymerize with a higher rate of random chain scissioning, thus, resulting in the non-thermal effects that were observed for microwave irradiation.

In contrast, the $E_{\mathrm{a}}$ appeared to be very sensitive to the temperature, and the effects of the temperature on the $E_{\mathrm{a}}$ increased as the temperature rose. Therefore, compared with the thermal depolymerization of heating, the reaction rate of PET depolymerization under microwave irradiation increased more quickly as the temperature rose, and this was also consistent with the results of the experiment.

\section{CONCLUSIONS}

The microwave depolymerization reaction of PET occurred simultaneously in the interior and on the exterior of PET. More than one kinetic process occurred because of the non-thermal effects of the microwave irradiation. The chain scissioning during PET depolymerization under microwave irradiation involved regular, then random and then again regular processes. Microwave irradiation made PET depolymerize with a higher rate of random chain scissioning events, resulting in the observed non-thermal effects of microwave irradiation. The reaction rate of PET depolymerization increased more quickly as the temperature rose. In this experiment, the depolymerization process was divided into two stages, that is, the stage before random chain scissioning and the stage after random chain scissioning. The corresponding activation energies were 142 and $378 \mathrm{~kJ} \mathrm{~mol}^{-1}$, respectively, which were much higher than that of the thermal depolymerization of heating.

\section{ACKNOWLEDGEMENTS}

We acknowledge the financial support from the National Natural Science Foundation of China (NSFC: 20474043 and NSFC: 20874074).

1 Krzan, A. Microwave irradiation as an energy source in poly(ethylene terephthalate) solvolysis. J. Appl. Polym. Sci 69, 1115-1118 (1998).

2 Klun, U. \& Krzan, A. Rapid microwave induced depolymerization of polyamide-6. Polymer 41, 4361-4365 (2000).

3 Shukla, S. R. \& Kulkarni, K. S. Depolymerization of poly(ethylene terephthalate) waste. J.Appl.Polym.Sci. 85, 1765-1770 (2002).

4 Sivalingam, G., Agarwal, N. \& Madras, G. Kinetics of microwave-assisted oxidative degradation of polystyrene in solution. AICHE J 49, 1821-1826 (2003).

5 Pingale, N.D. \& Shukla, S.R. Microwave-assisted aminolytic depolymerization of PET waste. Euro. Polym. J. 45, 2695-2700 (2009).

6 Liu, L.X., Zhang, D., An, L.J., Zhang, H.Y. \& Tian, Y.G. Hydrolytic depolymerization of poly(ethyleneterephthalate) under microwave irradiation. J. Appl. Polym. Sci. 95, 719-723 (2005)

7 Gedye, R. N., Smith, F. E. \& Westaway, K. C. The rapid synthesis of organic compounds microwave ovens. Can. J. Chem. 66, 17-26 (1988).

8 Sun, W. C., Guy, P. M., Jahngen, J. H., Rossomando, E. F. \& Jahngen, E. G. E. Microwave-induced hydrolysis of phospho anhydride bonds in nucleotide triphosphates. J. Org. Chem. 53, 4414-4416 (1988).

9 Lewis, D. A., Summers, J. S., Ward, T. C. \& McGrath, J. E. Accelerated imidization reactions using microwave radiation. J. Polym. Sci. PartA, Polym. Chem. 30, 1647-1653 (1992).

10 Shibata, C., Kashima, T. \& Ohuchi, K. Nonthermal influence of microwave power on chemical reactions. Jpn. J. Appl. Phys. 35, 316-319 (1996).

11 Wang, Y., Sun, H., Wang, B. \& Zhang, D. A study on thermal efficiency and non-thermal efficiency of microwave. Liaoning Chem. Ind. 35, 167-169 (2006).

12 Achilias, D. S., Redhwi, H. H., Siddiqui, M. N., Nikolaidis, A. K., Bikiaris, D. N. \& Karayannidis, G. P. Glycolytic depolymerization of PET waste in a microwave reactor. J. Appl. Polym. Sci. 118, 3066-3073 (2010).

13 Achilias, D. S., Tsintzou, G. P., Nikolaidis, A. K., Bikiaris, D. N. \& Karayannidis, G. P. Aminolytic depolymerization of poly(ethylene terephthalate) waste in a microwave reactor. Polym. Int. 60, 500-506 (2011)

14 Siddiqui, M. N., Achilias, D. S., Redhwi, H. H., Bikiaris, D. N., Katsogiannis, K- A. G. \& Karayannidis, G. P. Hydrolytic depolymerization of PET in a microwave reactor. Macromol. Mater. Eng. 295, 575-584 (2010).

15 Liu, X. \& Zhu, Z. A study on the regularities of equilibrium in the condensation polymerization processes of poly(ethylene terephthalate). Polyester Ind. 3, 7-10 (1994).

$16 \mathrm{Li}$, K., Song, X. \& Zhang, D. Depolymerization of poly(ethylene terephthalate) with catalyst under microwave radiation. J. Appl. Polym. Sci. 109, 298-1301 (2008).

17 Campanelli, J. R., Cooper, D. G. \& Kammal, M. R. A kinetic study of the hydrolytic degradation of polyethylene terephthalate at high temperatures. J. Appl. Polym. Sci. 48, 443-451 (1993).

18 Hosseini, S. S., Taheri, S. \& Zadhoush, A. Hydrolytic degradation of poly(ethylene terephthalate). J. Appl. Poly. Sci. 103, 2304-2309 (2007).

19 Kumar, H. S. \& Guria, C. J. Alkaline hydrolysis of waste poly(ethylene terephthalate): a modified shrinking core model. Macromol Sci. Part A. Pure. Appl.Chem. 42, 237-251 (2005)

20 Cai, F., Wei, J., Zhang, M. \& Chen, F. The effect of molecular weight of PET of its crystallization behaviour and thermal properties. J. Bei. Inst. Cloth. Tech. 11, 49-57 (1991).

21 Miyagi, A. \& Wunderlich, B. Etching of crystalline poly(ethylene terephthalate) by hydrolysis. J. Poly. Sci. 10, 2073-2083 (1972).

22 Launay, A., Thominette, F. \& Verdu, J. Water sorption in amorphous poly(ethylene terephthalate). J. Appl. Poly. Sci. 73, 1131-1137 (1999).

23 Launay, A., Thominette, F. \& Verdu, J. Hydrolysis of poly(ethylene terephtalate): a steric exclusion chromatography study. Polym. Degrad. Stab. 63, 385-389 (1999).

24 Ryynänen, S. The electromagnetic properties of food materials: a review of the basic principles. J. Food Eng. 26, 409-429 (1995). 